The International Journal of Indian Psychology

ISSN 2348-5396 (e) | ISSN: 2349-3429 (p)

Volume 5, Issue 1, DIP: 18.01.065/20170501

DOI: $10.25215 / 0501.065$

http://www.ijip.in | October-December, 2017

Research Article

\title{
Relationship between Body Image and Self Esteem: A Study on the Male Undergraduate Students of Delhi University
}

\author{
Maanya Tewatia ${ }^{1} *$
}

\section{ABSTRACT}

The purpose of this study was to examine how body image and self-esteem are related in a sample of Indian male students. The sample consisted of 132 males ranging from 18 to 21 years of age. Body image was assessed using the Appearance Evaluation subscale of the Multidimensional Body-Self Relations Questionnaire-Appearance Scales (MBSRQ-AS), while self-esteem was assessed using the Rosenberg Self-Esteem Scale. Using the scores on these scales, correlation values were computed. The results of the study concluded that higher self esteem is associated with a higher satisfaction with body image, as there was a significant positive correlation between the two $(+0.45)$. However, it was a moderate correlation. Thus, even though body image is not strongly tied to self esteem for all the participants, it is an important aspect of self esteem. The findings make a case for further research on the male population in the Indian context.

Keywords: Body Image, Self Esteem, Adolescents, Correlation

In describing ourselves, we undeniably make a reference to our bodies. Body image contributes to the perception of self in the society. The dimension of self that will be referred to in this paper is self-esteem. Self-esteem is one of the well-known constructs of psychology and has been defined in several ways. Morris Rosenberg (1965), the most well-known theorist in the area defined self-esteem as a favorable or unfavorable attitude towards the self. Another definition refers to self-esteem as the attitudinal and evaluative component of the self (Guindon, 2002). It involves feelings of worth and acceptance which are developed as a result of the awareness of our competencies and the feedback from the world around us.

Body-image, on the other hand, may be conceptualized as a multidimensional construct that represents how individuals "think, feel, and behave with regard to their own physical attributes" (Muth \& Cash, 1997). Two conceptually distinct components of body image have been identified by researchers. The first, body-image evaluation denotes individuals' evaluative thoughts and beliefs about their physical appearance. The second, body-image

\footnotetext{
${ }^{1}$ Dept. of Psychology, Jesus and Mary College, University of Delhi, New Delhi, India *Responding Author

Received: August 20, 2017; Revision Received: November 26, 2017; Accepted: December 05, 2017 (C) 2017 Tewatia M; licensee IJIP. This is an Open Access Research distributed under the terms of the Creative Commons Attribution License (www.creativecommons.org/licenses/by/2.0), which permits unrestricted use, distribution, and reproduction in any Medium, provided the original work is properly cited.
} 


\section{Relationship between Body Image and Self Esteem: A Study on the Male Undergraduate Students of Delhi University}

investment, refers to the behaviors individuals perform to manage or enhance the way they look (Cash \& Szymanski, 1995). The evaluative component of body-image is more closely related to self esteem as both the constructs share the common theme of self-evaluation.

However, dissatisfaction with body image has been thought to be a "woman's problem" traditionally (Pope, Phillips, \& Olivardia, 2000). As a result of this, men have often been ignored in psychological research on body image. Despite this, growing evidence suggests that men also have body image concerns and their concerns are on rise (Thompson \& Cafri, 2007). College men and women were found to be equally dissatisfied with their bodies (Olivardia, Pope, Mangweth, \& Hudson, 1995). Research indicates that majority of college male students endorse concerns about their appearance, have some form of body dissatisfaction, and exhibit a high drive for muscularity (Gray \& Ginsberg, 2007).

Unfortunately, it was only in the mid-1990's that men's body image issues became a subject of thorough research (Pope, Phillips, \& Olivardia, 2000). It has been found that in terms of seeking out professional help particularly for concerns about body image, men are less likely to do so (Addis \& Mahalik, 2003). Also, the social climate over the years has indicated to men that body preoccupation is effeminate and seeking help for such concerns carries shame and stigma (Pope et al., 2000). Moreover, a cultural perception has prevailed that as a group, men are protected from body image issues (Connan, 1998). Thus, a lack of research on male body image could be attributed to such cultural perceptions.

According to Davidson and McCabe (2006) poor body image may hamper adolescents' development of interpersonal skills and positive relations with peers. There is evidence that both the prevalence of body dissatisfaction and its impact on psychosocial functioning may be increasing in males (Hay, Mond \& Buttner, 2008). Also, for both boys and girls, poor body image has been associated with poor self-esteem (Eklund \& Bianco, 2000). Harter (1999) found that there is a common link between the self appraisals of physical appearance and self-esteem. The focus on appearance in making self-evaluations has been implicated in the low levels of self-esteem often observed in adolescence (Robins \& Trzesniewski, 2009). Moreover, self-esteem continues to decline during adolescence. Researchers have attributed this decline in self esteem to body image and other problems associated with puberty, the emerging capacity to think abstractly about one's self and one's future and therefore to acknowledge missed opportunities and failed expectations, and the transition to the more academically challenging and socially complex context of college (Robins \& Trzesniewski, 2009). Both low self-esteem and body dissatisfaction early in life have been found to predict a range of adverse health outcomes later in life, including the use of unhealthy weight-control behaviors, other eating-disordered behaviors, general psychological distress, and a variety of other negative outcomes (Kim \& Kim, 2009).

Hence, such research findings speak volumes about the need to focus on the status of the male college student population, with respect to their body image evaluations and self 


\section{Relationship between Body Image and Self Esteem: A Study on the Male Undergraduate Students of Delhi University}

esteem. Moreover, there has been a dearth of research studies that have been done in the Indian context regarding the same. Thus, this study aims to fill in the gap in literature and attempts to promote the development of interventions with a focus on the male population. It will serve as an important research finding in the Indian context.

\section{METHODOLOGY}

\section{Sample}

A total of 132 participants from various colleges of University of Delhi formed a part of the study ( $\mathrm{N}=132)$. All these participants had been selected keeping in mind that they were enrolled as a full-time undergraduate student in a college affiliated to the University of Delhi. The ages of the participants ranged from 18 to 21 years. All participants were selected using the convenience sampling method. A convenience sample can be defined as a sample in which research participants are selected based on their ease of availability. Essentially, individuals who are the most ready, willing, and able to participate in the study are the ones who are selected to participate (Saumure \& Given, 2008).

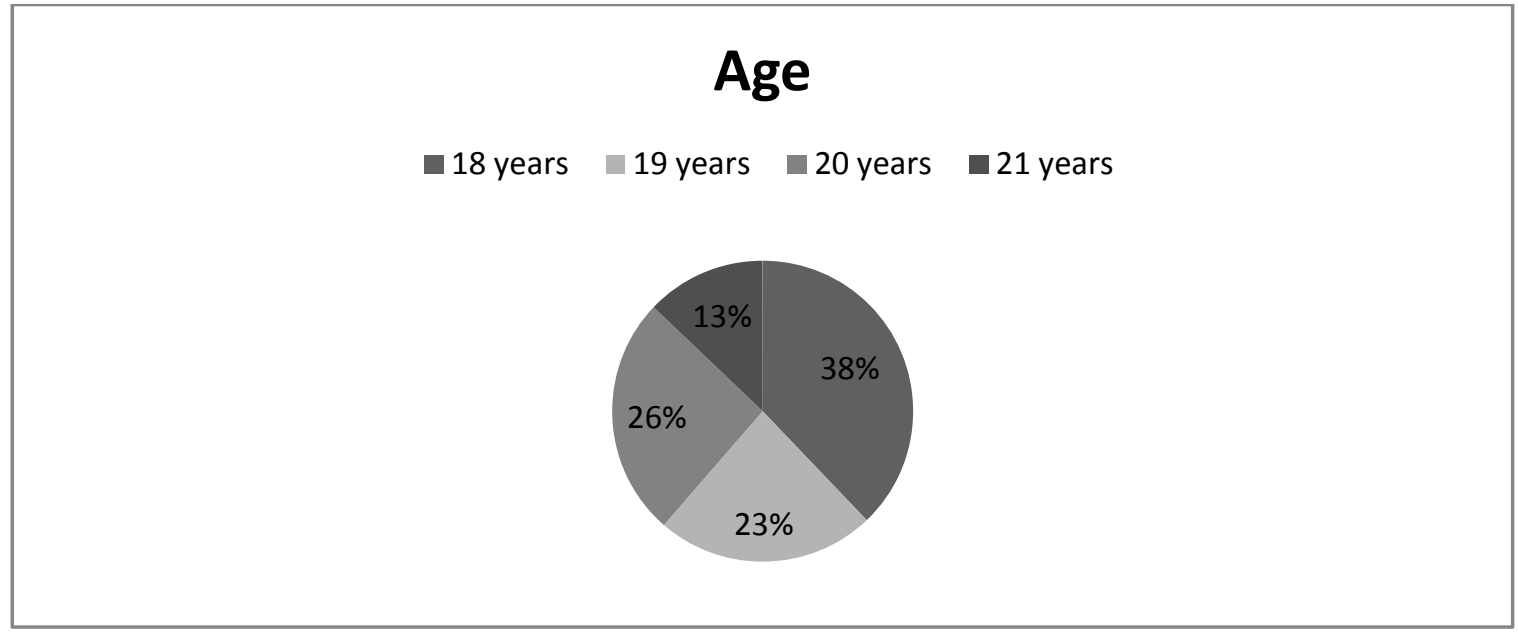

Figure 1. Pie chart depicting the age-wise distribution of participants $(N=132)$

\section{Design}

The design of the present study was the ex post facto design. Ex post facto literally means from what is done afterwards. It uses data already collected, and is ideal for conducting social research when it is not possible or acceptable to manipulate the characteristics of human participants. Ex post facto research is a method of teasing out possible antecedents of events that have happened but cannot be manipulated by the investigator (Simon \& Goes, 2013).

\section{Instruments}

Two measures were used in this study,

1. Rosenberg's Self Esteem Scale: The scale, developed by Dr. Morris Rosenberg, measures self-esteem by asking the respondents to reflect on their current feelings. It is a likert scale, consisting of ten items answered on a four-point scale- from strongly agree to strongly disagree. Five of the items have positively worded statements and five have negatively 


\section{Relationship between Body Image and Self Esteem: A Study on the Male Undergraduate Students of Delhi University}

worded ones. To score the items, value is assigned to each of the 10 items as- $3=$ strongly agree, $2=$ agree, $1=$ disagree and $0=$ Strongly Disagree. However, items 3,5,8,9 and 10 are reversed in valence. The score ranges from 0 -30, with 30 indicating the highest score possible. Typically, scores are around 22, with most people scoring between 15 and 25. A score of below 15 suggests low self-esteem. The scale generally has high reliability- testretest reliability is typically in the range of .82 to .88 , and Cronbach's alpha is in the range of .77 to .88 (Blascovich and Tomaka, 1993).

2. The Appearance Evaluation Scale: For the purpose of evaluating the participant's interpretation of his appearance, the Appearance Evaluation subscale of the Multidimensional Body-Self Relations Questionnaire-Appearance Scales (MBSRQ-AS) was used. It is the shorter version of the Multidimensional Body-Self Relations Questionnaire (MBSRQ), which is a 69-item self-report inventory for the assessment of self-attitudinal aspects of the bodyimage construct. The MBSRQ is for use with adults and adolescents (15 years or older). The Appearance Evaluation scale serves to assess the feelings of physical attractiveness, satisfaction or dissatisfaction with overall appearance. Those who score high feel mostly satisfied and positive about their appearance; the low scorers have a general unhappiness with their physical appearance. As Cash (2000) stated in his manual for the MBSRQ, the testretest reliability for the appearance evaluation subscale was .81 and Cronbach's alpha was found to be .88. The appearance evaluation scale has 7 items. The scale is scored by reversescoring items 6 and 7 and then averaging the scores for all items. The mean score is 3.49 and the standard deviation is .83. The appearance evaluation subscale was chosen as it assesses appraisals of overall appearance. The evaluative component of body-image is more closely related to self esteem as both the constructs share the common theme of self-evaluation. Hence, this scale was chosen.

\section{RESULTS}

Once data from each individual participant was collected, scores for the self esteem scale and the appearance evaluation scale were calculated. Using these scores, correlation values were computed. Karl Pearson's correlation method was used to find the value. The result is as follows-

Table 1: Correlation value

\begin{tabular}{|c|c|}
\hline & Self Esteem \\
\hline Body Image & 0.45 \\
\hline
\end{tabular}

The value of $r$ was found to be 0.45 . The result was significant at $p<0.01$. Even though technically it was found to be a positive correlation, the relationship between the variables did not come out to be very strong.

\section{DISCUSSION}

The present study aimed to understand the relationship of body image with self esteem among male college students of the University of Delhi. As shown in table 1, the domain of 


\section{Relationship between Body Image and Self Esteem: A Study on the Male Undergraduate Students of Delhi University}

self esteem positively correlated with body image $(+0.45)$. This means that higher self esteem would mean a positive body image evaluation and vice-versa. However, it was a moderate correlation based on which we can infer that a high self esteem doesn't necessarily mean a positive body image. Although a lot of research findings support the positive correlation between the two constructs, nevertheless, it is likely that self-esteem is not equally strongly tied to body satisfaction for all the adolescents. There could be many reasons behind the same.

All the participants had different personality dispositions and there was presence of a great deal of individual differences. The presence of different external factors such as family and social support, friends and media influences, environment at home, school and college, etc. could have different influences. For instance, one's family and friends might be supportive such that the person's self esteem will be boosted yet, at a personal level; he could be having a negative body image despite all the support. At times, even people with high self esteem may be easily influenced by the media and hence, they can start comparing their body with unrealistic standards, leading them to have negative body image evaluations. Also, in some cases, it could be possible that the participants would be having a positive body image but their self esteem might be low. The reasons for the low self-esteem could range from low academic performance, unsupportive family, lack of relationships, low social support etc. As identified by Robins and Trzesniewski (2009), the decline in self esteem could be attributed to not only body image, but also other problems associated with puberty such as the emerging capacity to think abstractly about one's self and one's future and therefore to acknowledge missed opportunities and failed expectations, and the transition to the more academically challenging and socially complex context of college.

Moreover, social desirability can influence the responses and scores of the participants. This is the limitation of self-report measures. Other sampling techniques could have been used as convenience sampling does not yield a very representative sample. Also, the tools used may not have been very accurate for the Indian context and could be a reason for discrepancy in the answers given. In this way, the correlation result between self esteem and body image would not be very specific. Hence, future researchers may overcome these limitations by using other sampling techniques to select a representative sample and using context-relevant tools.

However, the positive correlation is supported by the findings of various other studies that have been done previously. The focus on appearance in making self-evaluations has been implicated in the low levels of self-esteem often observed in adolescence (Robins \& Trzesniewski, 2009). Also, for both boys and girls, poor body image has been associated with poor self-esteem (Eklund \& Bianco, 2000). Harter (1999) found that there is a common link between the self appraisals of physical appearance and self-esteem. 


\section{Relationship between Body Image and Self Esteem: A Study on the Male Undergraduate Students of Delhi University}

Thus, even though body image is not strongly tied to self esteem for all the participants, it is an important aspect of self esteem. The findings also make a case for further research on the male population in the Indian context. Many programs have been created abroad that focus on self-esteem enhancement in adolescents. However interventions developed in the West cannot be implemented in India without modification, given the socio-cultural differences. Thus, this research finding may contribute in creating the need to focus on males when developing and evaluating interventions to enhance self esteem as well as to lessen the importance of appearance in adolescents' self-evaluations in India.

\section{Acknowledgments}

The author appreciates all those who participated in the study and helped to facilitate the research process.

Conflict of Interests: The author declared no conflict of interests.

\section{REFERENCES}

Addis, M. E., \& Mahalik, J. R. (2003). Men, masculinity, and the context of help seeking. American Psychologist, 58(1), 5-14.

Blascovich, J. \& Tomaka, J. (1991). Measures of self-esteem, in J. P. Robinson and P. R. Shaver (Eds.), Measures of Personality and Social Psychological Attitudes (San Diego, CA: Academic Press, 1991) 115-160.

Cash, T.F. (2000). The Multidimensional Body-Self Relations Questionnaire Manual. Third version.

Cash, T. F., \& Szymanski, M. L. (1995). The development and validation of the Body-image Ideals Questionnaire. Journal of Personality Assessment, 64, 466-477.

Connan, F. (1998). Machismo nervosa: An ominous variant of bulimia nervosa? European Eating Disorders Review, 6, 154-159.

Davidson, T.E., \& McCabe, M.P. (2006). Adolescent body image and psychosocial functioning. The Journal of Social Psychology, 146, 15-30.

Eklund, R. \& Bianco, T. (2000). Social physique Anxiety and Physical Activity Among Adolescents. Reclaiming Children and Youth, 9(3), 139.

Gray, J. J., \& Ginsberg, R. L. (2007). Muscle dissatisfaction: An overview of psychological and cultural research and theory. In J. K. Thompson, \& Cafri, G. (Eds.). The muscular ideal: Psychological, social, and medical perspectives, 15-40. Washington, DC: American Psychological Association.

Harter, S. (1999). The Construction of the Self: A Developmental Perspective. New York: Guilford Press.

Hay, P. J., Mond, J., Buttner, P., \& Darby, A. (2008). Eating Disorder Behaviors Are Increasing: Findings from Two Sequential Community Surveys in South Australia. PLoS ONE, 3(2), e1541. http://doi.org/10.1371/journal.pone.0001541. 


\section{Relationship between Body Image and Self Esteem: A Study on the Male Undergraduate Students of Delhi University}

Kim, D.S. \& Kim, H.S. (2009). Body-image dissatisfaction as a predictor of suicidal ideation among Korean boys and girls in different stages of adolescence: A two-year longitudinal study. The Journal of Adolescent Health, 45 (1), 47-54.

M.H. Guindon. (2002). Toward accountability in the use of the self-esteem construct. Journal of Counseling \& Development, 80(2), 204-214.

Muth, J. L., \& Cash, T. F. (1997). Body-image attitudes: What difference does gender make? Journal of Applied Social Psychology, 27, 1438-1452.

Olivardia, R., Pope, H. G., Mangweth, B., \& Hudson, J. I. (1995). Eating disorders in college men. American Journal of Psychiatry, 52, 1279-1285.

Pope, H. G., Phillips, K. A., \& Olivardia, R. (2000). The Adonis complex: The secret crisis of male body obsession. New York: The Free Press.

Robins, R.W. \& Trzesniewski, K.H. (2005). Self-esteem Development Across The Lifespan. Current Directions in Psychological Science, 14 (3), 158-62.

Rosenberg, M. (1965). Society and the adolescent self-image. Princeton, NJ: Princeton University Press.

Saumure, K. \& Given, L. (2008). Convenience sample. In L. M. Given (Ed.), The SAGE encyclopedia of qualitative research methods (pp. 125-125). Thousand Oaks, CA: SAGE Publications Ltd. doi: 10.4135/9781412963909.n68

Simon, M.K. \& Goes, J. (2013). Dissertation and Scholarly Research: Recipes for Success. Seattle, WA: Dissertation Success LLC

Thompson, J. K., \& Cafri, G. (2007). The muscular ideal: Psychological, social, and medical perspectives. Washington, DC: American Psychological Association.

Thompson, J.K. \& Smolak, L. (2001). Body image, eating disorders, and obesity in youth: Assessment, prevention, and treatment. Washington, DC: American Psychological Association.

How to cite this article: Tewatia M (2017). Relationship between Body Image and Self Esteem: A Study on the Male Undergraduate Students of Delhi University. International Journal of Indian Psychology, Vol. 5, (1), DIP: 18.01.065/20170501, DOI: 10.25215/0501.065 